\title{
Impacts of photovoltaic power source intermittence on a distribution network
}

\author{
Oumaïma Garfi ${ }^{1}$, Helmi Aloui ${ }^{2}$, Nadia Chaker ${ }^{3}$ \\ ${ }^{1}$ ISEM Research Team, Laboratory of Advanced Electronic Systems and Sustainable Energy (ESSE), ENIS, \\ University of Sfax, Tunisia \\ ${ }^{2,3}$ ISEM Research Team, Laboratory of Advanced Electronic Systems and Sustainable Energy (ESSE), ENET'Com, \\ University of Sfax, Tunisia
}

\begin{tabular}{l}
\hline \hline Article Info \\
\hline Article history: \\
Received Jun 19, 2018 \\
Revised Jul 19, 2019 \\
Accepted Jul 27, 2019 \\
\hline
\end{tabular}

Keywords:

Conventional generator Distribution power system Photovoltaic source PV intermittence

\begin{abstract}
The integration of the photovoltaic (PV) solar system to the existing distribution networks has brought new challenges to the network planners. One of the most interesting challenges is to prevent the impacts of the PV intermittent character on the steady state system operation conditions. So, the main aim of the present work is to investigate the effects of the PV power intermittence on voltage performance, conventional generator daily behavior and automatic voltage regulator operation. Simulations are effectuated on 33-bus IEEE radial distribution power system. And in order to provide a reliable study, a real PV power profile is adapted in this study. The considered network is modeled and simulated before and after the PV penetration and then a comparative study is established. Obtained results over a period of 24 hours revealed that the PV integration contributes to an enhancement of the overall voltage profile, a considerable saving in the total amount of the produced active power and a reduction of power losses; but on the other hand, the PV intermittent character causes significant transformation in buses voltages daily profiles as well as changes in production daily plan. To sum up, this paper reports the alterations, caused by the PV source intermittence, which must be taken into consideration by the distribution networks planners to maintain the overall network parameters within safe operating condition.
\end{abstract}

Copyright $\odot 2019$ Institute of Advanced Engineering and Science. All rights reserved.

\section{Corresponding Author:}

Oumaïma Garfi, ISEM Research Team,

Laboratory of Advanced Electronic Systems and Sustainable Energy (ESSE),

ENIS, University of Sfax,

Technology hub of Sfax, Tunis Road km 10, City El Ons, B.P. 1163, 3018, Sfax, Tunisia.

Email: oumaima.garfi@yahoo.fr

\section{INTRODUCTION}

In recent years, the electricity sector has seen an exponential development. In many countries a vast movement of deregulation appears. The causes (political will, economic interest, etc.) and the goals (improvement of electric companies, opening of new markets, etc.) of this movement of deregulation are very varied. One of the consequences of the deregulation of the electricity markets is the connection of new means of production [1]. The means used for this new electricity production are very diverse. There are wind farms, cogeneration plants, photovoltaic cells, small hydropower plants, fuel cells and other developments are expected in the future [2].

On the other hand a number of reasons such as: the obligation to reduce the emission of greenhouse gases, the diminution of fossil fuels, the issue of energy independence and sustainable development, have pushed to consider the energy problem not only from the economic point of view, but also from an ecological 
point of view $[3,4]$. This has encouraged many countries to develop their energy systems based on renewable energies [5].

Photovoltaic (PV) solar energy was first developed to meet electrical needs in isolated sites, such as mountain regions, islands and rural areas of developing countries. Since the early 2000s, the development of solar photovoltaic energy has grown exponentially. In fact, the installed capacity in the world has increased from a few Megawatts in the early 2000s to $102 \mathrm{GW}$ at the end of 2012 then $227 \mathrm{GW}$ at the end of 2015 and $300 \mathrm{GW}$ at the end of 2016. The installation rate of photovoltaic solar power is currently more than $70 \mathrm{GW}$ per year [6].

This significant growth of the PV installation has an important impact on the energy system behavior. For this reason, many research works have been conducted to study the effect of PV penetration on power systems. Farhad et al. [7] evaluated the application of custom power devices (DVR and DSTATCOM) to improve voltage unbalance in LV feeders with the presence of rooftops PVs. Another work [8] investigated the impact of a high PV insertion on steady state and transient transmission network stability. In [9] authors studied the effect of a PV with low voltage ride through (LVRT) capability on the transient stability of a synchronous generator connected to an infinite bus.

Although the already cited studies revealed effective outcomes in terms of the impacts of a high PV penetration, they generally eliminated the intermittent character of the solar power system. However, the variability of the PV output has significant consequences which must be completely studied before any other photovoltaic penetration. In light of this fact, the motivation of this work is to investigate the effects of the PV intermittence on the behavior of an existing distribution system. The penetration of such alternating power source brings a lot of new challenges from the system modeling and simulation point of view. The present research work proposes an efficient methodology and represents all the required models, permitting the examination of the alterations caused by the PV power output variations under a day period. To evaluate the proposed methodology and models, steady state and dynamic simulations are carried out on 33 bus networks where a PV source with a real production profile is connected. Then, the network voltage profile, the conventional generator daily behavior and the automatic voltage regulator operation are reported and analyzed to come up with a planning guide to adapting the regulation program, the power generation daily plan and the protection actions to the new system states.

To do so, firstly, a methodology of study is presented. Then, a simulation model is established. In the next section, the base case of the considered distribution network is simulated. Finally, the PV system is integrated to the network and a comparative study, with the base case, is effectuated to investigate the impacts of the PV intermittent character on the system daily behavior.

\section{METHODOLGY OF THE STUDY}

Due to the dependency of the PV production to the variation of climatic conditions, the solar PV source is characterized by its variable power output [10]. This intermittent character of the PV has the potential to alter the system daily operation in either negative or positive way [11]. For this reason, the intermittence of the PV source must be considered, and its impacts must be fully studied when analyzing the effects of connecting solar PV source to a distribution network.

As it is described on the flow chart of the study methodology (Figure 1), the analysis of the effects of the PV integration on system behavior is effectuated by comparison of the results of three simulations cases. The first case presents the network without any PV source connected (base case). In the next case, the PV with the maximum power production level (at solar noon period) is added to the network and then the whole system is simulated. Finally, the last case consists on the simulation of the network behavior over twenty-four hours by adapting a real profile of a PV daily production.

The study methodology is based on the modeling of the different components of the network and the simulation of the entire system under study. System modeling is completed on the basis of theoretical and technical studies. Modeling principles are explained in detail in the next section. For the network simulation, both steady state analysis and dynamic analysis are conducted. Indeed, simulations of the particular states of the system which are the base case (without PV) and the maximum PV production level case are established through a steady state simulation, i.e. based on power flow program execution. However, the simulation of the network with a PV production daily profile requires a dynamic simulation since the instability of the PV power output under a day period represents disturbances to the network. 


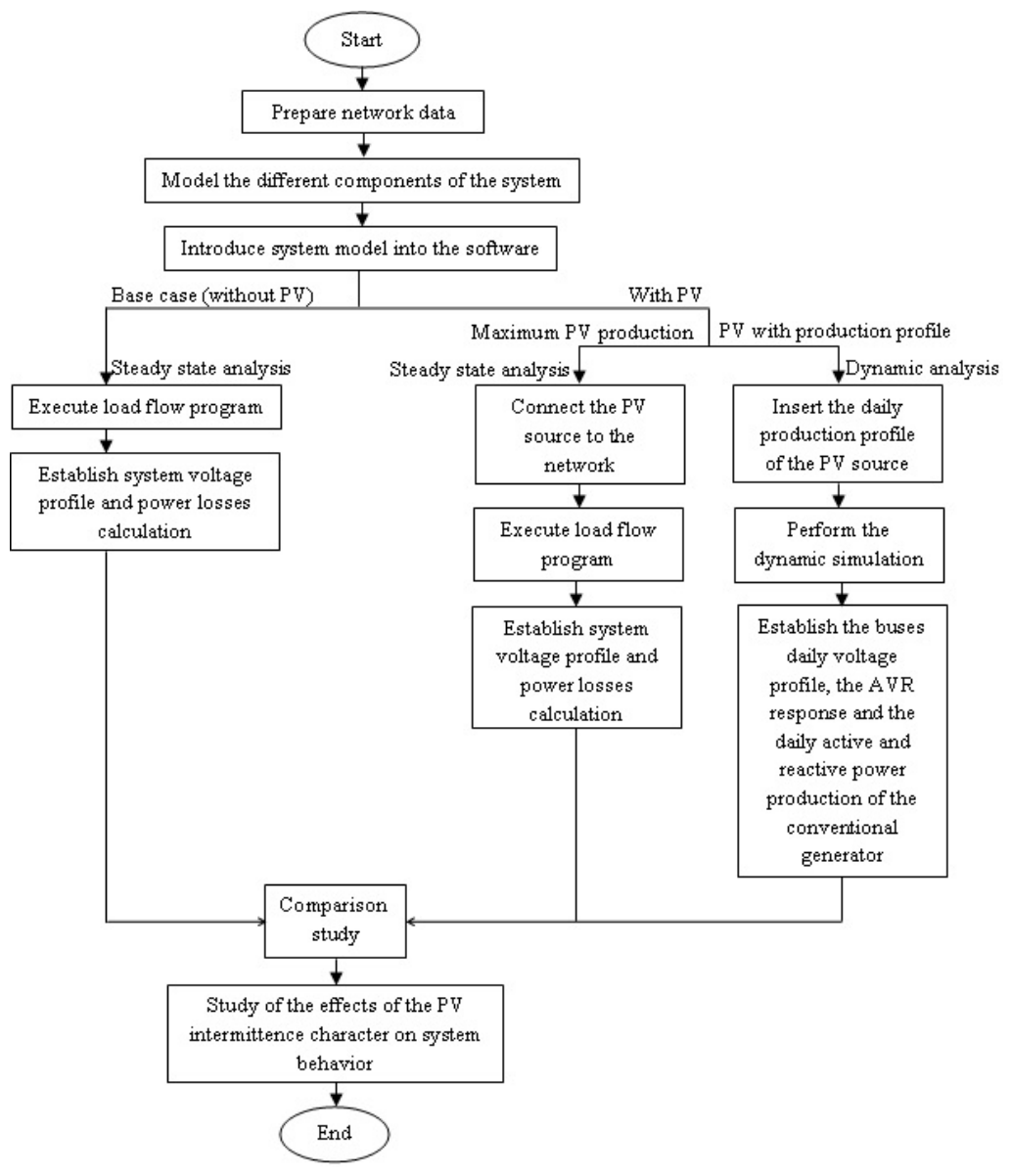

Figure 1. Flow chart of study methodology

\section{SIMULATION MODEL}

\subsection{Test system presentation}

Studies were effectuated on an IEEE standard network, which is a radial distribution system with a base voltage of $12.66 \mathrm{KV}$ and a base apparent power of 10MVAr. As shown in Figure 2 the network has a total of $32 \mathrm{PQ}$ buses with active/reactive power consumption of 3.715MW/2.3MVar and one slack bus where the conventional synchronous generator is connected. The solar photovoltaic system is concentrated at the 6th bus with a peak power generation of $2.4 \mathrm{MW}$.

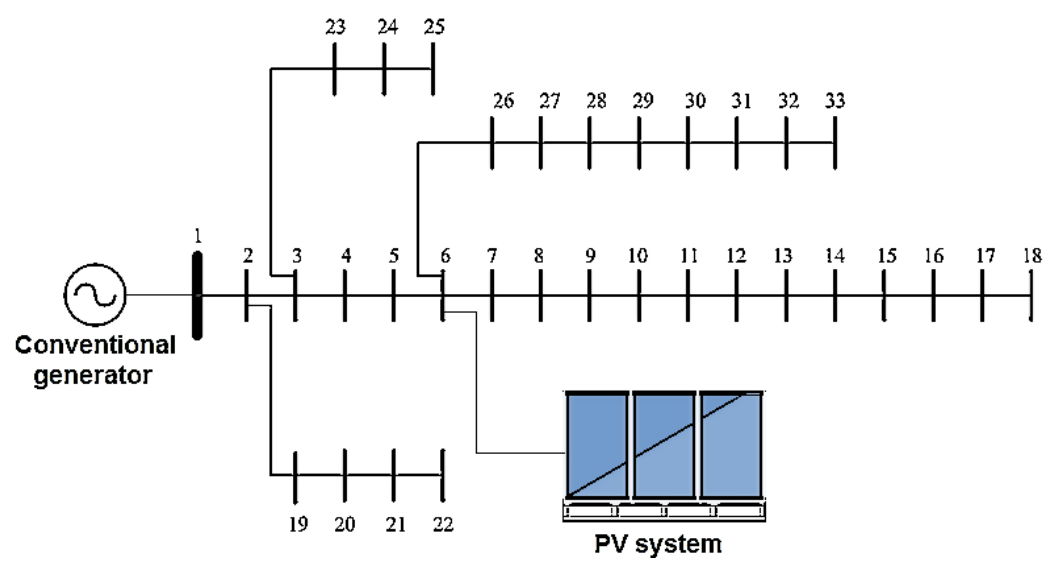

Figure 2. Test system presentation 


\subsection{Conventional generator model}

The conventional generator is a synchronous machine that is presented throughout the simulation with the classical generator transient model. The different generator parameters are depicted in Table 1.

Table 1. Synchronous generator parameters

\begin{tabular}{|c|c|c|c|}
\hline \multicolumn{4}{|c|}{ Generator Parameters } \\
\hline Un (KV) & 11 & $\mathrm{Xq}(\mathrm{pu})$ & 1.478 \\
\hline $\mathrm{Ra}(\mathrm{pu})$ & 0.0024 & $\mathrm{Xq}^{\prime}(\mathrm{pu})$ & 0.24 \\
\hline $\mathrm{Xi}(\mathrm{pu})$ & 0.0765 & Td' (s) & 2.35 \\
\hline $\mathrm{Xd}(\mathrm{pu})$ & 1.89 & $\mathrm{Tq} \mathrm{q}^{\prime}(\mathrm{s})$ & 1 \\
\hline $\mathrm{Xd}$ ' (pu) & 0.193 & H (MWs/MVA) & 1 \\
\hline
\end{tabular}

\subsection{Automatic voltage regulator model}

In order to maintain the terminal voltage of the generator constant, the synchronous generator is equipped with an Automatic Voltage Regulator (AVR). The AVR allows the control of the synchronous generators excitation voltage. The principle is to control the synchronous machine reactive power so that its terminal voltage kept at the AVR set value. And this set value is selected in order that the aimed voltage profile of the network is achieved. In fact, under excitation, the machine reacts as an inductor by absorbing reactive power thus inducing a drop in the grid voltage. In opposition, if it is overexcited it provides reactive power inducing an increase in the network voltage. Figure 3 shows a generalmodel of the automatic voltage regulator. The magnitude Vref, that represents the voltage set-point, is compared to the generator terminal voltage Vt. Then, the error is amplified to provide the requested excitation voltage Efd. The time constant and the gain of the amplifier are respectively Ta and Ka. The high and the low values of the excitation voltage (Efd_Max, Efd_Min) are fixed by a limiter system [12]. The AVR model parameters are fixed as follows $\mathrm{Ka}=20, \mathrm{Ta}=0.02$, Efd_Max=4 and Efd_Min=-4.

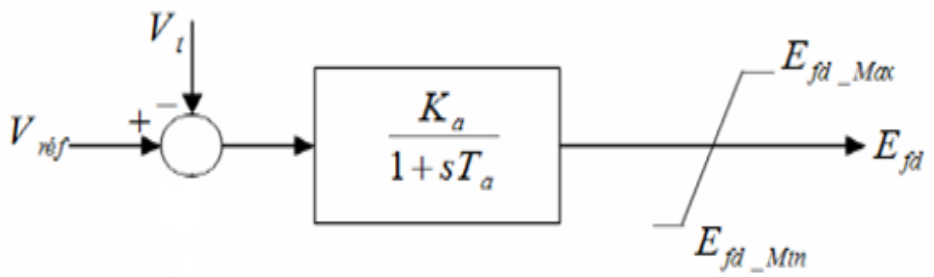

Figure 3. AVR general model

\subsection{Photovoltaic system model}

Throughout this work, it is presumed that the PV system doesn't have the potential to produce the reactive power. Hence, the bus with the PV system is modeled as PQ bus with a zero reactive load and a variable negative active load which presents the PV profile. The graph as shwon in Figure 4 illustrates a real photovoltaic production profile for different sizes: installation only, region and France [13]. In this study, the PV production profile of a region (green curve) will be adapted. The PV production is characterized by bell-shaped curve centered on solar noon. As it is observed, the power output increases slowly and it has a new value in every minute depending on the insolation variability. So, in order to simplify the data implementation of the PV production profile, we will consider that the PV output is constant during given periods and it is equal to the average power produced during those periods. The resulting profile is presented in the Figure 5 and it is employed throughout the simulation.

To calculate per unit normalized power output the (1) is used and the considered PV peak power $(2.4 \mathrm{MW})$ is exploited as a base value [14].

$$
\left(P_{P V}\right)_{p u}=\frac{P_{P V}}{\left(P_{P V}\right)_{\max }}
$$




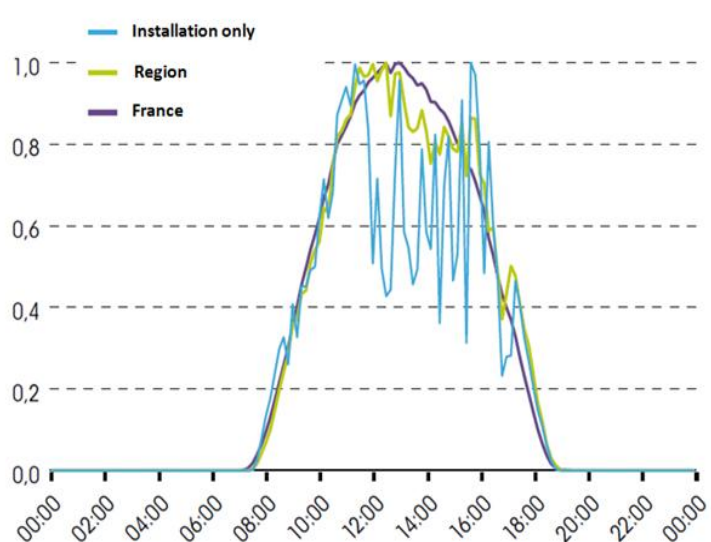

Figure 4. Real production profile for different sizes of photovoltaic source

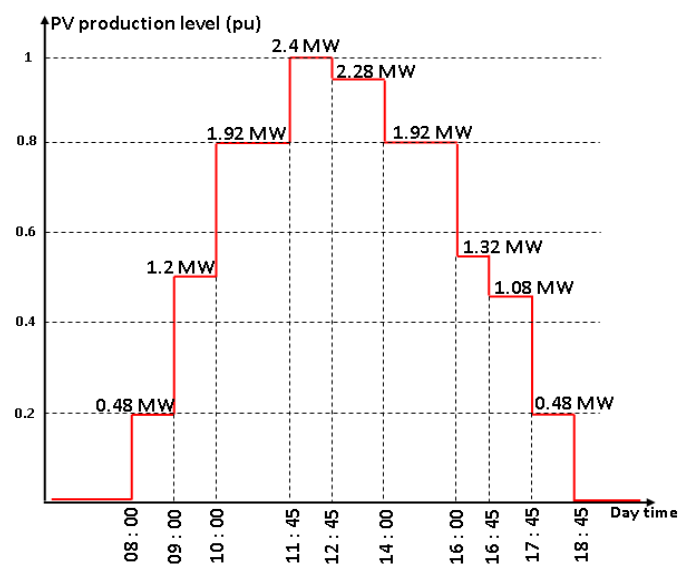

Figure 5. Photovoltaic power output profile adapted in this study

\section{BASE CASE}

Firstly, the distribution network is simulated without integrating the PV system. Load flow studies are performed using Newton Raphson method. From the obtained results, listed in Table 2, it can be observed that the voltage level ranges from $0.913 \mathrm{pu}$ (bus18) to $1 \mathrm{pu}$ (bus1), which means that voltages at all buses are within the operating limit; given that the admissible voltage range is within [90\%-105\%] of the nominal voltage. It is also mentioned in the same table that the active and the reactive synchronous generator production are respectively 3.918 MW and 2.435 MVar, with active and reactive losses of 0.203MW and 0.135 MVar.

Table 2. Power flow results of the base case

\begin{tabular}{|c|c|c|c|c|c|}
\hline \multicolumn{6}{|c|}{ Voltage level (pu) } \\
\hline Bus & Value & Bus & Value & Bus & Value \\
\hline 1 & 1 & 12 & 0,9268 & 23 & 0,9793 \\
\hline 2 & 0,997 & 13 & 0,9207 & 24 & 0,9726 \\
\hline 3 & 0,9829 & 14 & 0,9185 & 25 & 0,9693 \\
\hline 4 & 0,9754 & 15 & 0,917 & 26 & 0,9477 \\
\hline 5 & 0,968 & 16 & 0,9157 & 27 & 0,9451 \\
\hline 6 & 0,9496 & 17 & 0,9136 & 28 & 0,9337 \\
\hline 7 & 0,9461 & 18 & 0,913 & 29 & 0,9255 \\
\hline 8 & 0,9413 & 19 & 0,9965 & 30 & 0,9219 \\
\hline 9 & 0,935 & 20 & 0,9929 & 31 & 0,9178 \\
\hline 10 & 0,9292 & 21 & 0,9922 & 32 & 0,9168 \\
\hline \multirow[t]{2}{*}{11} & 0,9283 & 22 & 0,9916 & 33 & 0,9166 \\
\hline & & \multicolumn{2}{|c|}{ Active (MW) } & \multicolumn{2}{|c|}{ Reactive (MVar) } \\
\hline \multicolumn{2}{|c|}{ Total generation } & \multicolumn{2}{|c|}{3.918} & \multicolumn{2}{|c|}{2.435} \\
\hline \multicolumn{2}{|c|}{ Total loss } & \multicolumn{2}{|c|}{0.203} & \multicolumn{2}{|c|}{0.135} \\
\hline
\end{tabular}

\section{IMPACT ON SYSTEM BEHAVIOR}

At this stage, the already established PV system is integrated to the 33-bus IEEE distribution network. To investigate the effect of its intermittent nature on the network behavior, the PV production follows the previously plotted profile (Figure 5). As it is can be observed, against a period of 24 hours, the PV penetration level varies with different steps from $0 \%$ to $61.2 \%$, according to (2) [8]. So, the objective of the two next parts is to examine the impacts of those daily changes on voltage profile, synchronous generator behavior and AVR operation. To avoid reaching a high simulation time, assumption about the time scale has been set. Indeed, $1 \mathrm{~h}$ on the real curves corresponds to $10 \mathrm{~s}$ in simulation curves.

$$
\text { PV Penetration }(\%)=\frac{\text { PV Generation }(\mathrm{MW})}{\text { Base case total generation }(\mathrm{MW})}
$$

\subsection{Impact on voltage profile}

Simulation results demonstrate that the same voltage behavior is observed in all the network buses. Hence, only the most influential buses voltage variations are depicted in Figure 6. Such a figure shows the voltage profile of bus1, bus6 and bus 18 over a period of 24 hours. It is clear from the plots that voltage 
profiles of buses follow the PV generation profile. In other words, the voltage level rises with the increase of the PV production and declines with the decrease of the PV power output. Thus, voltage profile presents a maximum level during midday time, i.e. when the PV power output peaks, and it reaches its base case value during early morning and night time. So, we can conclude that the intermittent nature of the PV source causes a significant transformation in buses voltage daily behavior. Consequently, the voltage regulation planning must be updated in accordance with the resulting profiles. This study can also help operators to prevent when voltage violation is likely to happen and, most importantly, to take precautions to avoid overvoltage problem.

To verify the consequence of the maximum PV power injection, the overall voltage profile at solar noon is plotted in Figure 7. It is clear that the voltage magnitude is improved at all buses. Furthermore, all buses voltages are maintained within the permissible operating range and are very near to the nominal voltage. As an instance, the lowest voltage in the system (bus18) is improved from $0.913 \mathrm{pu}$ to $0.9855 \mathrm{pu}$. Although, in this case, voltage enhancement is obtained without causing voltage violation, overvoltage must be taken into account especially in the case of a variable consumption or once more distributed generations are added.

In the absence of the PV generation source, the power flow in the distribution network is unidirectional and its magnitude decreases with the increase of the distance from the conventional source. For this reason, in the base case, the voltage of the bus $23(0.9793 \mathrm{pu})$ is greater than that of the bus $4(0.9754 \mathrm{pu})$ and the bus 5 ( $0.968 \mathrm{pu})$. However, we can observe from the Figure 7 that, after integrating the PV source, the voltage of the bus $23(1.024 \mathrm{pu})$ became smaller than that of the bus $4(1.0258 \mathrm{pu})$ and the bus 5 (1.0244 pu). So, we can conclude that the implantation of the PV source in the network has caused a reversal of the power flow. This change can disturb the selectivity and the sensitivity of the protections. So, to avoid such problem, planners must review the protection plan based on the delivered results.

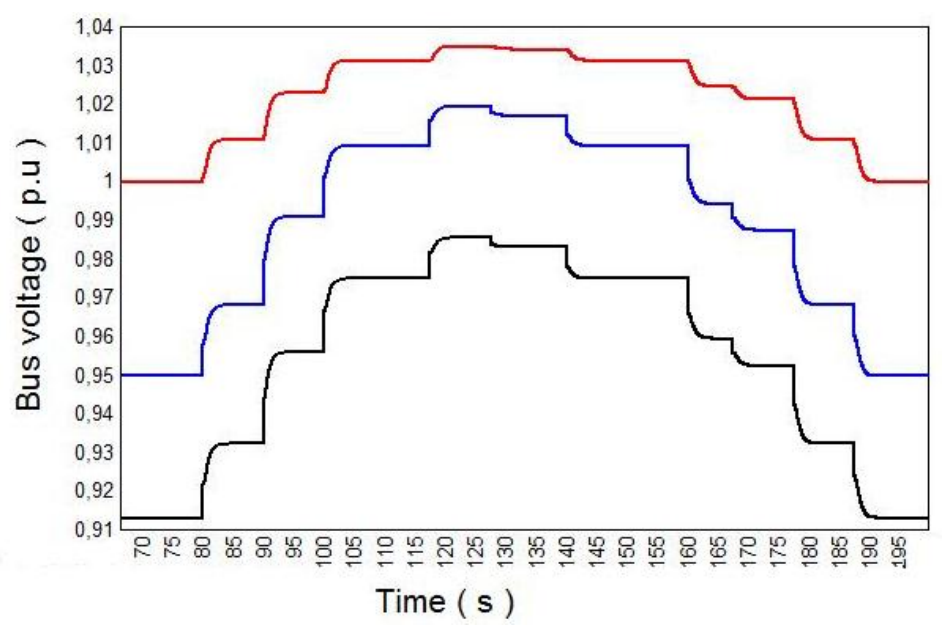

Figure 6. Daily voltage profile of bus1 (red), bus6 (blue) and bus18 (black)

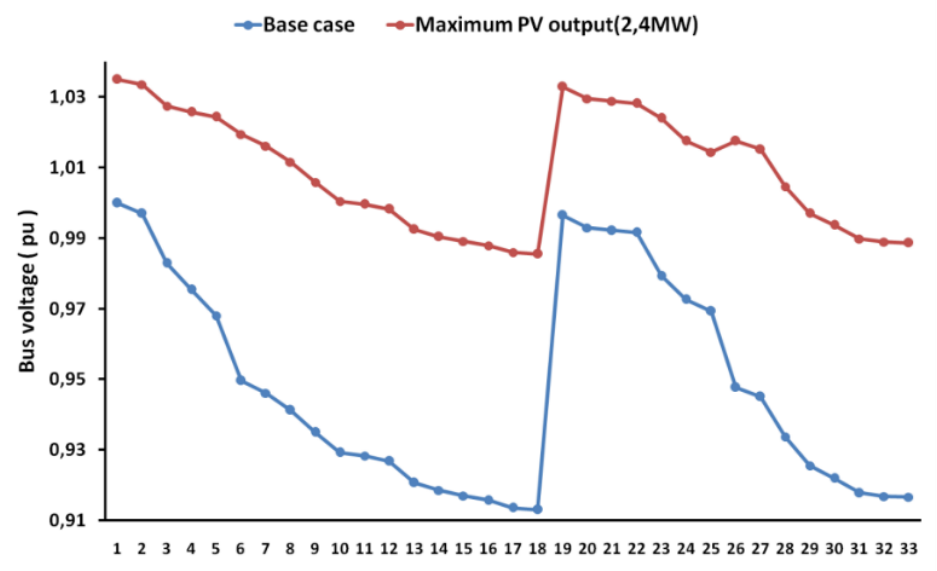

Bus

Figure 7. Voltage profile: base case (blue), with PV (red) 


\subsection{Impact on the synchronous generator behavior}

The automatic voltage regulator (AVR) is set to maintain the value of the generator terminal voltage close to $1 \mathrm{pu}$. But the implementation of the photovoltaic source leads to a variation in voltage magnitude. So, the AVR reacted, depending on the case, by decreasing or increasing the excitation voltage of the generator as shown in Figure 8. Indeed, conversely to the generator terminal voltage daily behavior as shown in Figure 9, the excitation voltage of the generator starts decreasing at the beginning of the day, and it reaches a minimum value during midday period, then, it increases gradually to attain its base case value at night.

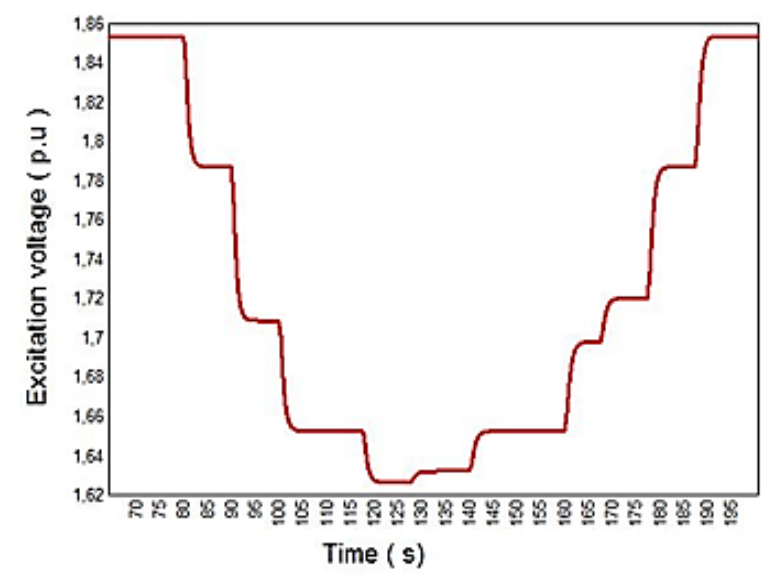

Figure 8. Excitation voltage of the conventional generator

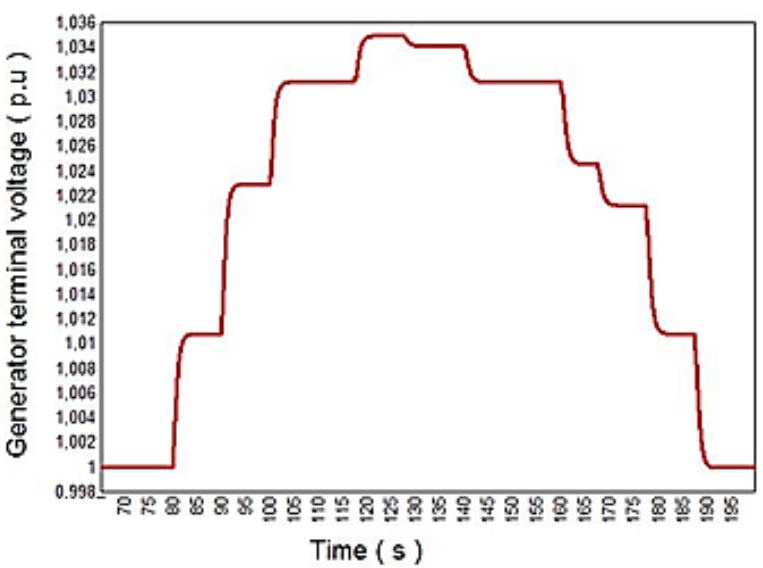

Figure 9. Terminal voltage of the conventional generator

The reactive power produced by the conventional generator over a period of 24 hours is presented in the Figure 10. Observed variations of the reactive power production are due to two reasons. The first is its dependency to the variation of the excitation voltage. And the second is the alteration in the daily behavior of the reactive power losses. In fact, in our case study, the reactive losses decrease with the increase of the PV level penetration and vice versa. So, to maintain the validity of the power supply-demand constraint, established in (3), the generated reactive power follows the same behavior of the reactive losses. Hence, it attains its minimum value (2.37 MVar) during midday period, i.e. when the reactive loss is at its minimum (0.07 MVar).

$$
Q_{G}+Q_{P V}=\sum_{i=1}^{N} Q_{D i}+Q_{L}
$$

Where $\mathrm{Q}_{\mathrm{G}}$ is the reactive power of the generator at the slack bus, $\mathrm{Q}_{\mathrm{PV}}$ is the reactive power of the $\mathrm{PV}$, $\mathrm{Q}_{\mathrm{Di}}$ is the reactive power demand at bus $\mathrm{i}, \mathrm{Q}_{\mathrm{L}}$ is the reactive power loss and $\mathrm{N}$ is the number of buses.

With the penetration of the PV system and in order to conserve the power balance, given in (4), the active power production must be divided between the conventional generator and the PV system. Consequently, as it is shown in Figure 11, the synchronous machine has adapted its production of active power according to the constraints induced by the intermittent nature of photovoltaic production. Indeed, the synchronous generator is operating now within a range of $3.918 \mathrm{MW}$ to $1.412 \mathrm{MW}$. Hence, corrective actions must be taken in programming and planning phase to adapt the daily production plan to those alterations.

$$
P_{G}+P_{P V}=\sum_{i=1}^{N} P_{D i}+P_{L}
$$

Where $\mathrm{P}_{\mathrm{G}}$ is the active power of the generator at the slack bus, $\mathrm{P}_{\mathrm{PV}}$ is the active power of the PV, $\mathrm{P}_{\mathrm{Di}}$ is the active power demand at bus $\mathrm{i}, \mathrm{P}_{\mathrm{L}}$ is the active power loss and $\mathrm{N}$ is the number of buses. 
We can notate from the Figure 10 and the Figure 11 that the conventional generator active power changes with a high rate contrary to the produced reactive power which varies with small rate, causing so alterations in the generator power factor. Indeed, the power factor of the conventional source drops to 0.512 at solar noon. However, operating the generators with a low power factor isn't preferred by the networks utilities because it alters negatively the overall power system efficiency [15]. Hence, protective actions can be planned to prevent conventional generator reaching this low power factor.

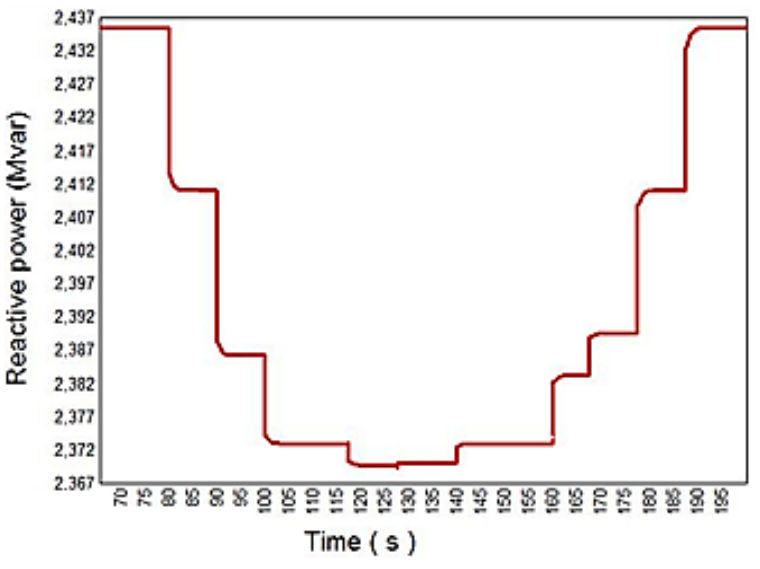

Figure 10. Reactive power of the conventional generator

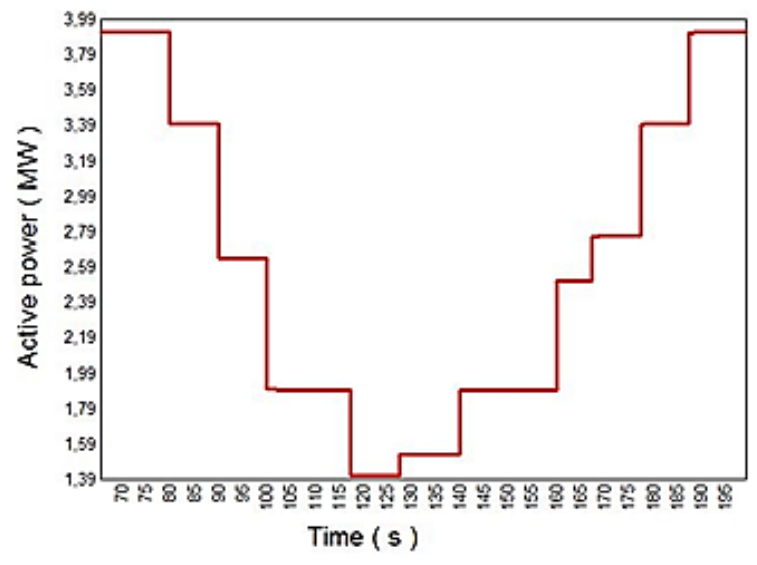

Figure 11. Active power of the conventional generator

\section{CONCLUSION}

This paper aims to study the effects of the PV source intermittence on the behavior of an existing distribution network. To do so, a real PV power output profile is chosen to be adapted in the present research work. Then, detailed simulations were conducted on a 33-bus IEEE radial distribution system. Firstly, load flow studies are effectuated to assess the steady state operation conditions before integrating the PV system. After, the PV power source is penetrated to the considered network and the effects of the PV power output intermittence are studied over a period of 24 hours. Obtained results demonstrate that the PV integration enhances the overall voltage profile and reduces both power losses and active power production. But on the other hand, the PV intermittent character results a considerable transformation in buses voltages daily profiles and an alteration on the power production plan. To avoid such problems, this work can help planning operators to make modification in the regulation program and also in the power generation daily plan. To conclude, in the context of an electrical power systems deregulation, the observation of a large number of such thematic simulations will allow to acquire a thorough knowledge about the behavior of the system in presence of an intermittent power source and hence to guide planners to decide on protection and defense actions.

\section{ACKNOWLEDGEMENTS}

The present work is financially supported by the Tunisian ministry of high education and scientific research.

\section{REFERENCES}

[1] Noppatee Sabpayakom, Somporn Sirisumrannukul, "Power Losses Reduction and Reliability Improvement in Distribution System with Very Small Power Producers," Energy Procedia, vol. 100, pp. 388-395, 2016.

[2] G. Matkar, D. K. Dheer, Vijay A.S., Suryanarayana Doolla, "A Simple Mathematical Approach to Assess the Impact of Solar PV Penetration on Voltage Profile of Distribution Network," 2017 National Power Electronics Conference (NPEC) College of Engineering Pune, India, vol. 18-20, 2017

[3] Anton Johannes Veldhuisa, Matthew Leach, Aidong Yang, "The impact of increased decentralised generation on the reliability of an existing electricity network," Applied Energy, vol. 215, pp. 479-502, 2018.

[4] Salah Eddine Mankour, Ahmed Wahid Belarbi, Mohammed Tarik Benmessaoud, "Modeling and Simulation of a Photovoltaic Field for $13 \mathrm{KW}$," International Journal of Electrical and Computer Engineering (IJECE), vol. 7(6), pp. 3271-3281, 2017. 
[5] Edison Banguero, Hector David Agudelo Arias, Andrés Julián Aristizábal Cardona, Daniel Hernán Ospina Barragánd, "Renewable microgrid operational results and economic evaluation using RETScreenTM," International Journal of Electrical and Computer Engineering (IJECE), vol. 9(2), pp. 723-731, 2019

[6] F Urban, S Geall, Y Wang, "Solar PV and solar water heaters in China: Different pathways to low carbon energy," Renewable and Sustainable Energy Reviews, vol. 64, pp. 531-542, 2016.

[7] Farhad Shahnia, Arindam Ghosh, Gerard Ledwich, FiruzZare, "Voltage unbalance improvement in low voltage residential feeders with rooftop PVs using custom power devices," International Journal of Electrical Power \& Energy Systems, vol. 55, pp. 362-377, 2014.

[8] Sara Eftekharnejad, Vijay Vittal, Gerald Thomas Heydt, Brian Keel, Jeffrey Loehr, "Impact of Increased Penetration of Photovoltaic Generation on Power Systems," IEEE Transactions On Power Systems, vol. 28(2), 2013.

[9] M. Yagami, J.Tamura, "Impact of High-Penetration Photovoltaic on Synchronous Generator Stability," 2012 International Conference on Electrical Machines (ICEM), 2011.

[10] D. Chinna Kullay Reddy, S. Satyanarayana, V. Ganesh, "Design of Hybrid Solar Wind Energy System in a Microgrid with MPPT Techniques," International Journal of Electrical and Computer Engineering (IJECE), vol. 8(2), pp. 730-740, 2018

[11] Mohammad H. Alomari, Jehad Adeeb, and Ola Younis, "Solar Photovoltaic Power Forecasting in Jordan using Artificial Neural Networks," International Journal of Electrical and Computer Engineering (IJECE,) vol. 8(1), pp. 497-504, 2018.

[12] Behnam Feizifa, Omer Usta, Mahmoud Reza Haghifam, "Impact of Distributed Generation on Transient-Based Fault LocationTechniques in Distribution Networks," IEEJ Transactions On Electrical And Electronic Engineeringieej Trans 2015, vol. 10, pp. 242-248, 2015.

[13] Panorama de l'électricité renouvelable au 30 juin 2016 [Online]. Available: https://www.rtefrance.com/sites/default/files/panorama_enr2016.pdf

[14] ArmağanTemiz, AbdulmajeedM.Almalki, ÖzgürKahraman, "Investigation of MV Distribution Networks with High-Penetration Distributed PVs: Study for an Urban Area," Energy Procedia, vol 141, pp. 517-524, 2017.

[15] Davud Mostofa Tobnaghi, “A Review on Impacts of Grid-Connected PV System on Distribution Networks," World Academy of Science, Engineering and Technology International Journal of Electrical and Computer Engineering, vol. 10(1), 2016. 